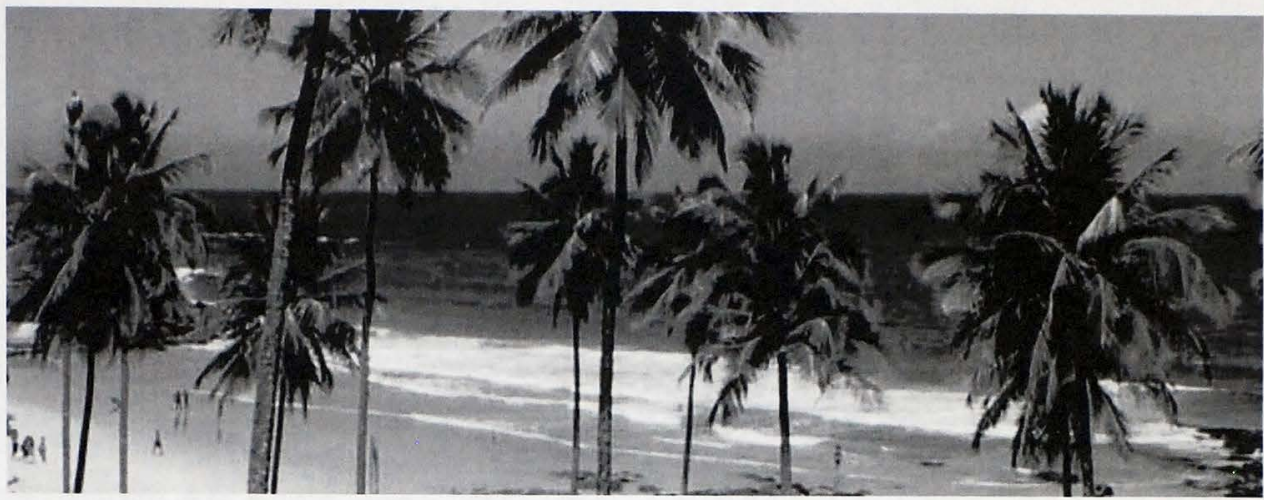

Turismo y capital social en El Salvador: Una reflexión desde la antropología del desarrollo

\author{
Ramón D. Rivas
}

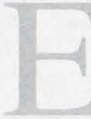

n este artículo se reflexiona de una manera implícita sobre la vinculación turismo y desarrollo comunal.

También trata en forma crítica las condiciones en las que las instancias involucradas y las comunidades tienen que abordar tan importante tema, sobre todo cuando este se ha convertido en punta de lanza para el desarrollo nacional. Partimos de que un empuje turístico que deje por un lado el factor sociocultural - todo lo que ello conlleva como elemento identitario - es considerado como algo intruso a las sociedades depositarias de ese factor.

Durante los últimos años, la práctica del turismo cultural ha crecido significativamente por todo el mundo, teniendo unos efectos positivos indudables en el entorno social, funcional, urbanístico y patrimonial de los lugares de destino, convirtiéndose en uno de los fondos de provisión de recursos para el desarrollo de políticas de protección y rehabilitación del patrimonio. Nuestro país en lo que a eso respecta está aun en pañales. Es por ello que urge encontrar mecanismos que solventen esta situación y con ello dar respuestas efectivas. Urge la formación de los profesionales del sector turístico pero en el marco de una estrategia de desarrollo cultural nacional.
Antropología y desarrollo o antropología para el desarrollo. Puntos para la reflexión.

La antropología para el desarrollo y la antropología del desarrollo se echan en cara recíprocamente sus propios defectos y limitaciones. Los antropólogos para el desarrollo consideran las críticas postestructuralistas moralmente erróneas porque a su entender conducen a la falta de compromiso en un mundo que urge de la aportación de la antropología ${ }^{1}$. Se considera que centrarse en el discurso es pasar por alto cuestiones que tienen que ver con el poder, ya que la pobreza, el subdesarrollo, y la opresión no son cuestio-

\footnotetext{
' Al respecto: Horowitz M. Development anthropology in the Mid- 1990s.' Development Anthropology Network 12(1 y 2). 1994. Págs. 1-14.
} 
nes de lenguaje sino cuestiones históricas, políticas y económicas. Esta interpretación de la antropología del desarrollo proviene claramente de una falta de comprensión del enfoque postestructuralista, el cual - tal como sus defensores alegan - trata de las condiciones materiales del poder, de la historia, de la cultura y de la identidad. Abundando en esta reflexión, los antropólogos para el desarrollo aducen que la crítica postestructuralista es una pirueta intelectual propia de intelectuales occidentales que no responde de ningún modo a los problemas intelectuales o políticos del Tercer Mundo $^{2}$ se pasa por alto intencionadamente el hecho de que los intelectuales del Tercer Mundo se hayan situado a la vanguardia de esta crítica y que un número creciente de movimientos sociales lo encuentren útil y les sirva como punto de referencia. Por su parte, para los críticos, la antropología para el desarrollo es profundamente problemática porque subscribe un marco de referencia - el desarrollo - que ha posibilitado una política cultural de dominio sobre el Tercer Mundo. Trabajar en general para instituciones como el Banco Mundial y para procesos de 'desarrollo inducido' representa para los críticos parte del problema y no parte de la solución ${ }^{3}$. La antropología del desarrollo saca a la luz la violencia silenciosa contenida en el discurso del desarrollo a la vez que los antropólogos para el desarrollo, a ojos de sus críticos, no pueden ser absueltos de esta violencia.

Estas diferencias son muy significativas ya que mientras que los antropólogos para el desarrollo se concentran en la evolución de sus proyectos, en

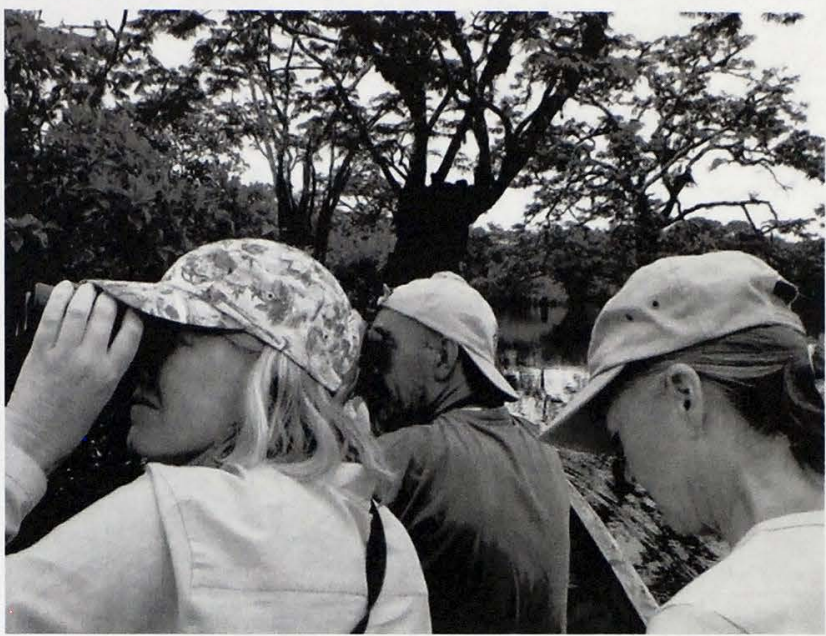

el uso del conocimiento para elaborar proyectos a la medida de la situación y de la cultura de sus beneficiarios, así como en la posibilidad de contribuir a paliar las necesidades de los pobres, los antropólogos del desarrollo centran sus análisis en el aparato institucional, en los vínculos con el poder que establece el conocimiento especializado, en el análisis etnográfico y la crítica de los modelos modernistas, así como en la posibilidad de contribuir a los proyectos políticos de los desfavorecidos. Quizá el punto más débil de la antropología para el desarrollo sea la ausencia de una teoría de intervención que vaya más allá de las intervenciones retóricas sobre la necesidad de trabajar en favor de los pobres. De modo similar, la antropología para el desarrollo sugiere que el punto más débil de la antropología del desarrollo no es tan diferente: estriba en cómo dar un sentido práctico a sus críticas teóricas. La política de la antropología del desarrollo se basa en su capacidad para proponer alternativas, en su sintonía con las luchas a favor del derecho a la diferencia, en su capacidad para reconocer focos de resistencia comunitaria capaces de recrear identidades culturales, así como en su intento de airear una fuente de poder que se había mantenido oculta. Pero nada de ello constituye un programa elaborado en profundidad con vistas al 'desarrollo alternativo'

Es también oportuno decir que toda esta discusión poco a poco a llevado a abordar la relación existente entre los discursos del desarrollo y la identidad y en ello se presta cada vez más atención. ¿De qué modo ha contribuido este discurso a moldear las identidades de pueblos de todas partes del mundo? ¿Qué diferencias pueden detectarse, en este sentido, entre clases, sexos, razas y lugares? Los trabajos sobre hibridación cultural pueden in-

\footnotetext{
${ }^{2}$ Al respecto: Little, P., y Painter, M. 'Discourse, politics, and the development process: Reflections on Escobar's 'Anthropology and the Development Encounter'.' American Ethnologist 22(3). 1995. Pp. 602- 609.

${ }^{3}$ Véase: Escobar, A. 'Anthropology and the development encounter: The Making and marketing of development anthropology.' American Ethnologist 18(4): 658-682. PP. 1991.
} 
Turismo y capital social en El Salvador:

Una reflexión desde la antropología del desarrollo

terpretarse a la luz de esta consideración ${ }^{4}$. Otro aspecto de la cuestión de la subjetividad que en parte ha recibido atención es la investigación antropológica de la circulación de conceptos de desarrollo y de modernidad en ámbitos del Tercer Mundo. ¿Cómo se usan estos conceptos y cómo se transforman? ¿Cuáles son sus efectos y su manera de funcionar una vez han penetrado en una localidad del Tercer Mundo? ¿Cuál es su relación tanto con las historias locales como a los procesos globales? ¿Cómo se procesan las condiciones globales en ámbitos locales, incluyendo aquéllas de desarrollo y modernidad? ¿En qué modos concretos las utiliza la gente para negociar sus identidades? ? $^{5}$ Pero es más y aquí nos vamos adentrando al tema que este artículo nos motiva: ¿Cómo concibe la gente el desarrollo partiendo del turismo en países del Tercer Mundo y concretamente en nuestro país?

El análisis del desarrollo como discurso ha conseguido crear un subcampo, la antropología del desarrollo, relacionada pero distinta de otros subcampos inspirados por la economía política, el cambio cultural u otros marcos de referencia aparecidos en los últimos años. Al aplicar teorías y métodos desarrollados fundamentalmente en el ámbito de las humanidades a antiguos problemas de las ciencias sociales (desarrollo, economía, sociedad), la antropología del desarrollo ha per- mitido a los investigadores situarse en otros espacios distintos desde los cuales contemplar la realidad de un modo diferente. Actualmente se está prestando atención a aspectos tales como: los antecedentes históricos del desarrollo, particularmente la transición desde la situación colonial hasta la de desarrollo; los perfiles etnográficos de instituciones de desarrollo concretas (desde el Banco Mundial hasta las ONG progresistas), así como de lenguajes y subcampos; la investigación de las protestas y resistencias que se oponen a las intervenciones ligadas al desarrollo; y biografías y autobiografías críticas de los encargados de llevar a la práctica el desarrollo. Estas investigaciones producen una visión más matizada de la naturaleza y de los modos de funcionar de los discursos en favor del desarrollo que los análisis de los años ochenta y principios de los noventa parecían sugerir.

\section{Desarrollo y turismo nacional}

¿Existe en la mentalidad del salvadoreño una idea de lo que significa el turismo, de la importancia de este para el desarrollo o no de la comunidad? ¿Cómo concibe el salvadoreño promedio los momentos de descanso y los sitios de esparcimiento y entretenimiento educativo? ¿La idea de convertir al El Salvador en un país de atractivo turístico es un proyecto del gobierno? ¿Qué participación tiene la co- munidad en ello? ¿Se encuentra el Estado salvadoreño preparado para iniciar una política de turismo a nivel nacional?

Muchos proyectos de desarrollo han fracasado históricamente por ignorar las condiciones socioculturales ${ }^{6}$ de las comunidades. El antropólogo y psicólogo social holandés Gerrit Huizer $(1980)^{7}$ estudiando "la desconfianza del campesino y sus funciones" cuenta cómo en San Juancito, en el valle de La Esperanza, allá en Jucuapa, Chinameca, en 1955 técnicos de San Salvador en una iniciativa que apoyaba la Organización de las Naciones Unidad para la Agricultura y la Alimentación FAO, por su siglas en inglés, acusaron a los campesinos de "obstructores del desarrollo", ya que se opusieron a colaborar en un proyecto de agua potable.

Los campesinos, necesitados de agua, todos levantaron la mano cuando se les dijo que el proyecto se iba a llevar a cabo siempre y cuando ellos colaboraran con mano de obra. $\mathrm{Al}$ momento de iniciar el proyecto, los campesinos no llegaron. Huizer investigó, con trabajo de campo, el por qué de la negativa de los campesinos a colaborar. Los pobladores se negaron en forma pasiva, pues sabían que el proyecto no les iba a favorecer en nada, sino solo a un campesino rico que era el dueño de la tierra en donde se iban a abrir los pozos. George M. Foster ${ }^{8}$ cuenta tam-

\footnotetext{
${ }^{4}$ Al respecto: García Canclini, N. Culturas híbridas: Estrategias para entrar y salir de la modernidad. México, D.F.: Grijalbo. 1990 . P. 67.

${ }^{5}$ Véase: Dahl, G., y Rabo. A., eds. Kam-ap or Take-off. Local notions of development. Stockholm: Stockholm Studies in Social Anthropology. 1992.P. 35.
}

\footnotetext{
${ }^{6}$ Por condiciones socioculturales no sólo quiero dar a entender la forma de vida de la gente en sus comunidades y las condiciones en que se encuentran, la forma en que ellos desarrollan el ciclo de la vida, es decir, las poblaciones indígenas y el campesinado, grupos marginales en la ciudad y en el campo, los "pobres", etc., sino también a la forma en que ellos tratan de sobresalir de esa situación y formas de resistencia que ellos ofrecen al llamado "cambio" y, sobre todo, por qué esa resistencia al cambio.

${ }^{7}$ Al respecto: Gerrit Huizer. El Potencial revolucionario del campesino en América Latina. Siglo XXI Editores. México. (quinta edición en español. 1980. Pp. 45, 46, 47 y 48. (Primera edición 1973)

${ }^{8}$ Foster, George. M. Antropología aplicada. Fondo de Cultura Económica, México 1995. P. 63.
} 


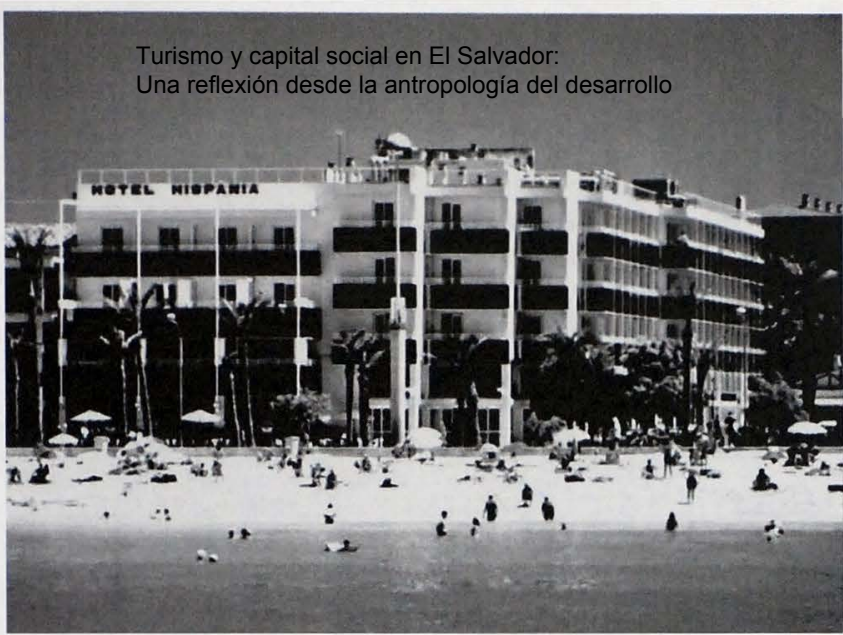

bién cómo los esfuerzos del gobierno mexicano por mejorar la salubridad de las aldeas a través de la potabilización de las aguas resultaron, durante largo tiempo, infructuosos. Realizadas desde la óptica de los ingenieros y siguiendo el modelo de instalación sanitaria urbana occidental, los técnicos planificaron y construyeron una serie de lavaderos en los pueblos para evitar que las aldeanas llevaran la ropa al río en condiciones desfavorables. Cuando los proyectos estuvieron terminados, los técnicos comprobaron con sorpresa que las aldeanas, lejos de estar agradecidas, no tenían ningún interés en la innovación. Investigaciones posteriores demostraron que las aldeanas aprovechaban las coladas en el río para comunicarse, intercambiarse noticias de la aldea e informaciones importantes sobre nacimientos, muertes, parcelas en venta, etc. Como resultado, los ingenieros modificaron los lavaderos de manera que las al- deanas quedasen unas frente a otras y pudieran seguir con su interacción social.

Estos casos ilustran las paradojas del desarrollo cuando sólo es visto desde la óptica técnica y financiera. Como resultado muchas veces los técnicos de desarrollo quedan decepcionados por la "ingratitud" de aquellos a los que han ayudado con su esfuerzo; los califican de "ingratos", "subdesarrotender la modernidad".

Este es sólo un ejemplo de intervención en la que no se tiene en cuenta la cultura del destinatario: sucede con frecuencia que muchas familias que viven cerca de los "lugares turísticos" no ven una fuente de ingresos en los turistas, ya que estos son "encerrados por las empresas en sus propios centros", y por ellos no son confrontados con la comunidad. Los pobladores y llados", "vagos" o "incapaces de en- la comunidad muchas veces son evadidos o simplemente no se toman en cuenta?

Como se ha visto, uno de los campos en los que es más evidente la contribución práctica de la antropología es la llamada "ayuda al desarrollo". La relación de los antropólogos con el desarrollo se califica como ambivalente porque, de una parte, los especialistas en ciencias son básicos para llevar a cabo cualquier proyecto de desarrollo en otras culturas. Por otra parte, el concepto de desarrollo es fuertemente contestado por los antropólogos, precisamente a causa de su cercanía con las personas a quienes se presta la ayuda para el desarrollo.

La principal crítica al desarrollo proviene del hecho de que es un concepto construido a partir del nacionalismo. ${ }^{10}$ Al finalizar la segunda guerra mundial, los Estados Unidos se encontraron como la potencia hegemónica de Occidente. Con la victoria aliada llegó el desmantelamiento de los viejos imperios coloniales europeos en favor del dominio comercial y militar norteamericano. Hasta entonces los estados coloniales habían ocupado amplias zonas del mundo no europeo con el fin de explotar sus materias primas a bajo precio para transformar aquellas metrópolis. Este proceso se legitimó en nombre de la civilización. Había que "civilizar" a los "salvajes" (antes del siglo XIX la legitimación moral consistía en evangelizarlos) hasta que pudiesen adquirir el nivel cultural y económico de los europeos. Bajo esta

\footnotetext{
${ }^{9} \mathrm{Al}$ momento de realizar un estudio en Suchitoto, comprobamos de los mismos pobladores su descontento pues algunos manifestaron molestia ya que los proyectos turísticos no les beneficiaban directamente a muchos de ellos. Se quejaban de que el turismo sólo llegaba a los hoteles y restaurantes grandes y eso se debía por el hecho que los planificadores de los viajes a los turistas en las oficinas de San Salvador no les no les tomaban en cuenta. Véase al respecto: Ramón Rivas, et al. Deseo local y patrimonio histórico en Suchitoto. Facultad de Arte y Cultura. No. 3. Colección Antropología. Universidad Tecnológica de El Salvador. TecnoImpresos. Abril. 2005.

${ }^{10}$ Juan Carlos Gimeno y Pilar Monreal, (editores): La Controversia del desarrollo. Instituto Universitario de Desarrollo y Cooperación (Universi dad Complutense de Madrid), Madrid 1999.
} 
Turismo y capital social en El Salvador:

Una reflexión desde la antropología del desarrollo

idea subyace la creencia en la superioridad intelectual, biológica y cultural de los occidentales frente a los no occidentales y la idea darwinista de la evolución, según la cual unos pueblos estaban más evolucionados que otros, pero que con el tiempo todos podrían adquirir el mismo nivel cultural ${ }^{11}$.

Si bien la idea de la superioridad racial occidental desapareció tras la segunda guerra mundial, no desapareció la idea evolucionista de que los pueblos y las economías tienen una evolución lineal (de la cual Occidente sería el culmen) y que quienes no están a la altura de Occidente sencillamente se encuentran en una etapa previa de desarrollo.

La medida del desarrollo la daba el bienestar material medido en indicadores con relación a los mismos indicadores de las metrópolis. La renta per cápita (el producto interior bruto) el número de hospitales, automóviles o teléfonos, se consideraban indicadores de desarrollo. Como resultado, muchas poblaciones con un nivel de vida material bajo en comparación a Occidente, pero suficiente o incluso elevado con respecto a su entorno, eran definidos como subdesarrollados. Un ejemplo: la producción de arroz por hectárea en Nepal era 200 veces inferior a la de Japón; sin embargo, los agricultores nepalíes no sólo tenían cubiertas sus necesidades y generaban excedente, sino que con los largos tallos del arroz nepalí obtenían forraje para su ganado. No obstante, desde el punto de vista cuantitativo se los consideraba pobres y se aconsejó la implantación del arroz japonés con consecuencias negativas para la economía local ${ }^{12}$.

Países enteros como Colombia, México, Costa Rica, Venezuela y Brasil, fueron clasificados como subdesarrollados o pobres en los años 40 y 50 del siglo $\mathrm{XX}$, aunque únicamente sucedía que sus ingresos comparados con los de Estados Unidos eran menores. Las políticas de desarrollo internacionales transformaron a países de bajo nivel de vida material relativo en países pobres y miserables.

Asumiendo que era deseable que estos países alcanzaran mediante el empleo de la ciencia y la tecnología el nivel de vida de Occidente, surgieron instituciones, organizaciones y políticas orientadas a este fin (Banco Mundial, Fondo Monetario Internacional) que al final reproducían el modelo de dependencia de las antiguas colonias por la ayuda externa ${ }^{13}$. Más tarde, con la retirada del Estado de muchas esferas y la privatización de algunos servicios públicos, también se privatizó la ayuda al desarrollo, lo que explica el auge de las organizaciones no gubernamentales, que son asociaciones privadas de ayuda financiadas por sus socios y donantes particulares, por empresas y por Estados donantes.

Muchos autores, especialmente Escobar y Portes, criticaron que esta visión del desarrollo es un nuevo "encuentro colonial" "14 a través del cual los pueblos del Tercer Mundo han sido objetivados y controlados por Occidente en la segunda mitad del siglo XX por medios diferentes al imperialismo del siglo XIX. pp. $15-28$

Rivas, R. D.

Siendo verdad que si del 1600 al 1800 se "evangelizaba", en 1900 se "civilizaba" y en el siglo XX se "desarrollaba" (ahora se desarrolla "sosteniblemente" y se "codesarrolla") como discurso legitimador de prácticas de dominación, no es menos cierto que los críticos olvidan mencionar el rol de los pueblos colonizados, de sus actores (elites, técnicos, etnias, clases sociales, etc.) en esta relación, y qué usos e interpretaciones han hecho del desarrollo.

Es en este doble contexto - crítica al concepto de desarrollo y aparición de organizaciones no estatales - cuando los antropólogos empiezan a actuar en el campo del desarrollo y a aplicar sus conocimientos. La creciente participación de antropólogos en las agencias internacionales, organismos gubernamentales, ONG y fundaciones "se corresponde con un cambio de enfoque en la práctica de proyectos y programas cuando comienza a tener en cuenta la necesidad de poner a la gente primero" 15 . De manera que los antropólogos toman el rol de interlocutores entre las comunidades beneficiarias de los programas y las agencias.

Si en los años setenta su papel fue llamar la atención sobre la pérdida de recursos que suponía el enfoque tecnocrático $^{16}$, en los años 80 se convirtieron en antropólogos forenses ${ }^{17}$ que diagnosticaban las razones de las muertes de los proyectos ${ }^{18}$. Hoy muchos antropólogos participan activamente, tanto como ejecutores (técnicos) de las políticas de desarrollo como en el papel de consultores o

${ }^{11}$ De aquí procede la falsa creencia de que los pueblos "primitivos" nos permiten conocer cómo fueron los antepasados prehistóricos de los europeos.

${ }^{12}$ Foster, George, M. Antropología aplicada. Op. Cit, p. 43.

${ }^{13}$ Juan Carlos Gimeno y Pilar Monreal, (editores): La Controversia del desarrollo. Op. Cit. Pág. 47.

${ }^{14}$ A Escobar.: Anthropology and the colonial encounter. American Ethnologist, $\mathrm{n}^{\circ} 18$ (4), 1991. P. 18 


\section{Turismo y capital social en El Salvador:} Una reflexión desde la antropología del desarrollo

diseñadores de estas políticas. ${ }^{19}$ La pregunta es ¿por qué hoy en día el factor turismo ha venido a reemplazar muchas otras iniciativas que en otras décadas se utilizaron como elementos claves para el desarrollo de los pueblo? No será que hoy se dan cuenta que eso de trabajar directamente con la población en el Desarrollo de la comunidad" conllevó a situaciones no deseadas y que ahora se ha visto en el elemento turismo un factor aparentemente mucho más impersonal y por ende fácil de manejar. Por lo menos eso parece para muchos.

¿Qué hacen hoy en día los antropólogos en las agencias que promueven el turismo? La experiencia ha demostrado que los antropólogos muy bien pueden dar aportes significativos en la búsqueda de involucrar más a las comunidades en esa afanosa tarea del turismo cultural. En este artículo quiero hacer énfasis en que, para poder desarrollar un verdadero turismo cultural, se necesita de saber aprovechar los recursos que el medio ofrece, $y$ en esto nos referimos a esos hechos tangibles e intangibles. No se trata ya de copiar modelos y estratégicas de otros países, ya que cada país tiene que ser visto en su propio contexto. Y, además, tomar en consideración que en muchos casos la gente ve el desarrollo en función del aprovechamiento adecuado de su entorno. La experiencia ha demostrado que cuando las comunidades no se involucran, esto va en detrimento de la formación de capital social y de la autogestión comunitaria.

\section{Caracterización del turismo en nuestro medio, el pueblo y las ins- tancias que lo fomentan.}

Antes de iniciar la reflexión considero importante lanzar estas preguntas: ¿Qué significado tiene para el salvadoreño promedio eso que se conoce como "turismo"? ¿Sabe el grosso de la población la importancia que el turismo puede tener para el desarrollo de la nación?, ¿qué significa para el grueso de la población descansar o "día libre”? ¿De qué manera aprovecha el salvadoreño los lugares de esparcimiento? Y, volviendo a las preguntas generadoras al inicio de este artículo: ¿La idea de convertir al El Salvador en un país de atractivo turístico es un proyecto del gobierno? ¿Qué participación tiene la comunidad en ello? ¿Se encuentra el Estado salvadoreño preparado para iniciar una política de turismo a nivel nacional?

Considero que, antes de pasar a dar respuesta a estas pregunta, es importante delimitar el fenómeno y concretizarlo en lo que ahora percibimos, así: los factores turismo son los hechos sociales que conforman la realidad turística, pueden ser extrínsecos e in-

\footnotetext{
15 Juan Carlos Gimeno y Pilar Monreal, (editores): La Controversia del desarrollo. Op. Cit. Pág. 47.

${ }^{16}$ Foster, George. M. Antropología aplicada. Op. Cit, p. 46.

17 Juan Carlos Gimeno y Pilar Monreal, (editores): La Controversia del desarrollo. Op. Cit. Pág. 67.

${ }^{18}$ Conrad Phiilip Kottak. "Cuando no se da prioridad a la gente. Algunas lecturas sociológicas de proyectos terminados" en Primero la gente, M. Cernea (coord.) Fondo de Cultura Ecopnómica, México. 1995

${ }^{19}$ Michael Cernea. (coord.) Primero la gente. Fondo de Cultura Económica, México. 1995. P. 78.
}

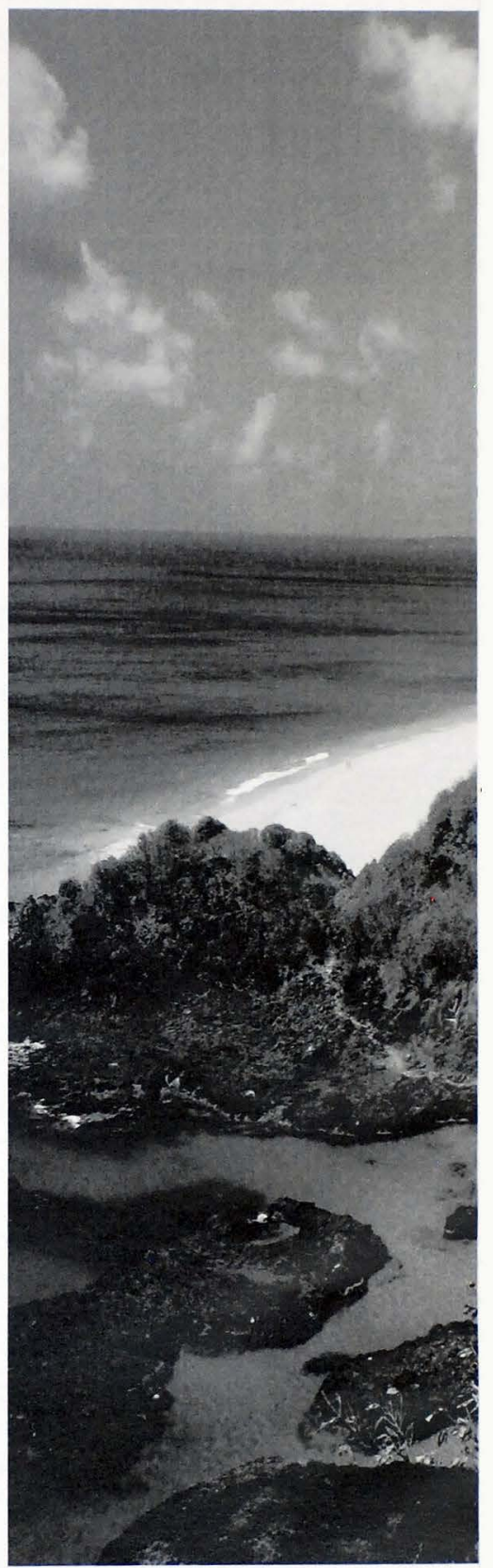

Septiembre 2007, $\mathrm{N}^{\circ} .39$ 


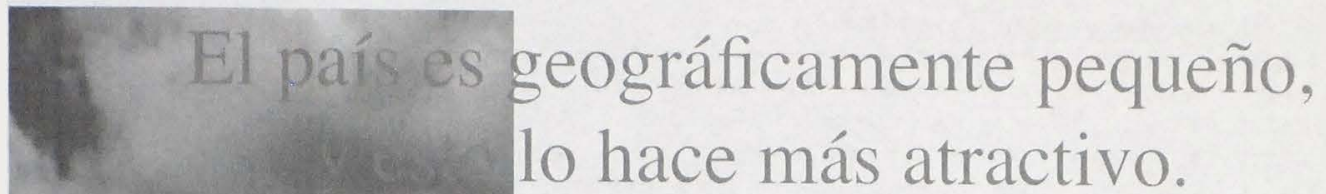

trínsicos. Estos factores se encuentran en todos los países, con sus características específicas en las estructuras, infraestructuras e instituciones.

Para que el sistema turístico pueda funcionar se requiere de atractivos también turísticos; Además, la dotación de bienes y servicios que sostengan las estructuras sociales y productivas, tales como educación, salud, vivienda, transporte, carreteras, puentes, teléfonos, etc.

El Salvador tiene un sistema de comunicaciones y de transporte que coadyuva su existencia. La mayor parte de las ciudades y lugares con atractivo turístico o con potencial, cuentan con servicios públicos de agua potable, electricidad, servicios de alimentación, etc. ¿Está preparada la gente común y corriente para recibir y atender al turista?

El país es geográficamente pequeño, $y$ esto lo hace más atractivo. Por su parte en lo referente al factor extrínseco, vemos que este es proporcionado por el gobierno a través de su administración. Habría que ver en que medida es que el gobierno concibe el turismo, si el mismo es solo una herramienta para concebir más divisas o si verdaderamente es para contribuir al desarrollo - en el amplio sentido de la palabra - de la comunidad. El hecho es que en nuestra sociedad existe una fuerte disparidad en todos los sectores que conformamos, $y$ es enorme, $y$ eso es precisamente lo que hace para unos el turismo sea visto como potencial de disfrute, para otros como un medio de subsistencia. En definitiva, lo que para unos es paseo para otros es una forma de vida.

A lo largo y ancho del país, en casi todos los rincones hay elementos naturales y como tal se les quiere sacar ventaja de lo que son y significan en el marco de lugares significativos para el esparcimiento individual y social; lagos, ríos, volcanes, acantilados, esteros, playas, miradores, etc. Así como también; la amplia y variada producción artesanal, diversas y significativas formas culinarias, expresiones artísticas en las que sobresalen la danza y la música también tradicional, las fiestas patronales con sus ricas y variadas tradiciones que varían de lugar en lugar y de acuerdo a la época del año en que se celebren; pero, además todas esas expresiones culturales que se presentan en la forma de elementos tangibles y que salen de la espontaneidad del pueblo, principalmente los fines de semana.

Es por ello que son muchas las instituciones que están involucradas con el turismo; ocupando el primer lugar está el Ministerio de Turismo, que le compete formular la política nacional en ese rubro, regular las facilidades turísticas y estimular la colaboración de la empresa privada.

Indirectamente hay otras instituciones que por la cercanía que, tienen con el patrimonio tangible e intangible su trabajo en muchos aspectos, se entrelazan con el Ministerio de Turismo, el Ministerio de Relaciones Exteriores, el ISTU, Concultura y Casart, entre otros. No obstante las actividades están debidamente delimitadas, aun- 
que parece ser que hay algún tipo de coordinación. Sí debe quedar claro que el elemento turismo es un hecho que trastoca la vida socioeconómica, política y, por ende, cultural del país. Ahora bien, si nos fijamos en las preguntas formuladas al inicio de este apartado, ¿tenemos todos claro lo que esto implica?

Fundamentos de juicio por tomar en consideración

El Estado de El Salvador, como responsable directo de las acciones culturales y turísticas del país, debe fundamentarse en una investigación cuidadosa de la revalorización de los bienes culturales tangibles e intangibles, el estudio de la toponimia, la práctica de un calendario de fiestas tradicionales, del conocimiento de los monumentos que nos enseñan la cultura del pasado para comprender el presente e intuir el futuro, y de la comprensión de nuestros símbolos nacionales.

En El Salvador, la fundamentación turística, necesita de una relación armónica entre los servicios que se ofrecen llámense turísticos o la conservación del patrimonio se debe hacer conciencia entre los que disfrutan de ese entretenimiento que hay que cuidarlo, ya que de nada sirve sembrar árboles cada año durante el inicio de invierno cuando en el verano abundan los incendios; de nada sirve promover la visita a las playas cuando pasados los días de vacaciones abundan los montones de basura; cuando en el menor descuido se manchan los sitios arqueológicos y otros monumentos históricos; cuando la basura abunda en las calles del país; cuando las entradas de las ciudades son verdaderos botaderos de basura; cuando los "auto-talleres" abundan en cualquier parte y a cualquier lado de las calles y cuando los residuos que estos emanan son tirados en cualquier lugar; cuando en la mentalidad del ciudadano no existe aquel compromiso de cuidar lo que aún nos ofrece la flora y la fauna. Si reflexionamos sobre estos aspectos, bien vale hacernos las preguntas: $¿ \mathrm{~A}$ qué fomento del turismo nos estamos refiriendo? ¿Qué es lo que queremos ofrecer?

Por lo tanto, se deben ejercer acciones inmediatas para mejorar dicha relación, haciendo conciencia de lo que tenemos y de su importancia, entrenando adecuadamente al personal que trabaja y que debe atender al turismo. A menudo se escuchan voces de descontento para con los oficiales de migración de las oficinas de migración en las fronteras terrestres y en el aeropuerto. Lo mismo se dice de los empleados de migración en la ciudad capital: gente mal encarada y hasta mal intencionada y a veces sin la mínima seña de haber cursado algún nivel de relaciones públicas; lo mismo equivale para las agencias de viajes y guías de turismo, aunque aquí puede ser más controlable por el hecho ser tratarse de instancias privadas. Los sectores públicos si dejan mucho que desear. Urge incluir en los programas de estudio nociones básicas de la historia y la cultura nacional, inculcando el cuido y respeto por el patrimonio, respetando a los creadores y portadores de la cultura popular, concientizando sobre la función de los símbolos nacionales en la identidad nacional.
Es necesario tomar muy en consideración que, en lo referente al proyecto de nación en El Salvador, este no existe. Las comunidades salvadoreñas se encuentran en medio de la disputa por el poder comunal entre diversos sectores sociales sin una unidad, sin una meta en común, cada quien defiende sus propios intereses.

Es necesario analizar cuáles son las deficiencias que la sociedad salvadoreña tiene para poder entrar, en una forma ventajosa, en un proyecto y en este caso, el proyecto turístico, que es lo que diferentes estudios de la Facultad Latinoamericana de Ciencia Sociales (FLACSO) a nivel centroamericano apuntan. Pero la cuestión es que en esa red social necesaria para emprender un proyecto turístico se encuentra todo un engranaje de elementos que hay que tomar en consideración, pero lo más importante es el factor educación.

Considero que si no hay un proyecto nacional de educación que se enfoque directamente al estudio de la historia -y con ello la importancia del patrimonio tangible e intangible del que es rico el país - no se podrá avanzar, por muy buenas intensiones que presenten los que dirigen y coordinan las políticas nacionales que aunque sean cortoplacistas contienen elementos de

Urge incluir en los programas de estudio nociones básicas de la historia y la cultura nacional, inculcando el cuido y respeto por el patrimonio, respetando a los creadores y portadores de la cultura popular, concientizando sobre la función de los símbolos nacionales en la identidad nacional. 
Turismo y capital social en El Salvador:

Una reflexión desde la antropología del desarrollo

juicio y son positivas para la el país. La educación es clave, y, sobre todo, en esas comunidades en donde los proyectos se ejecutan. Si no hay capital comunal no puede haber desarrollo social ni turístico; no hay que olvidar que es precisamente en esas comunidades en donde por muy sencillas que parezcan, es donde, se encuentra toda una reestructuración del tejido social: patriarcalismo, polarización social, polarización ideológica, liderazgo comunal y religiosidad.

Es necesario entonces un mayor apropiamiento por parte de las comunidades de la historia y del patrimonio nacional. Que ellos, los pobladores, vean que el turismo les trae beneficios. Pero, ¿qué pasa con esos megaproyectos de turismo que llegan a las comunidades, las cercan, y excluyen de una vez a los pobladores? Son pobladores de otros lugares, a lo mejor de otros países los que llegan a trabajar allí y, es más, la gente ya ni sabe lo que allí, en donde ellos han nacido y crecido, ahora toma lugar.

Cuando la gente de la comunidad no es involucrada se puede convertir en obstructor, y eso hay que evitarlo a toda costa. Experiencias de otros países nos demuestran que el turismo bien planificado se convierte en agente dinámico de cultura, crea posibilidades de empleo e infraestructura, impulsa el comercio y facilita a la población local; $y$, al turista en general, le da el conocimiento de sus lugares, sus tradiciones y sus costumbres. Lo he experimentado en España, en Italia, en Portugal y hasta en Grecia. La gente se llega a sentir orgullosa de su lugar, de su país, y a eso es que considero que hay que apuntarle en nuestro país

Pero la cuestión es que cuando no hay un sentimiento de nación, esto queda en manos del mercado, de las grandes compañías transnacionales del turismo y se traduce en una pérdida de soberanía y de los recursos naturales, sociales y hasta culturales de la nación en detrimento de esas comunidades y en ganancia de las transnacionales.

\section{¿De qué sirve invertir} en turismo cuando estos centros de recreación se convierten en lugares exclusivos en donde los

\section{nacionales no tienen ni}

el dinero ni la cultura

turística para valorar esa cultura turística?

Proyectos de esta naturaleza ya existen en El Salvador y están convirtiendo al salvadoreño en extraño en su propia tierra. Esos hechos que la gente de las localidades repite año con año - dígase fiestas, bailes, comidas típicas y otras formas emanadas de la cultura, como bien cultural - son desperdiciados, ya que no son utilizados por el gran significado histórico y cultural para mostrárselos al que llega como turista, y muchas veces se falsifican hechos en la forma de vestidos, danzas y hasta formas de actuar cuando en la realidad cada pueblo a lo largo $y$ ancho del país es rico en cultura y tradición.

Es necesario estudiar, buscar lo que existe y darle el valor que tiene. En El Salvador, las políticas culturales son de folklorización. Se ha llegado al extremo de ideologizar las manifestaciones culturales, y cuando esto sucede es porque se le quiere sacar contenido a algo; ya no es natural. Cuando la cultura es vista y hecha de esta manera ya entra en la trama del poder. El Estado debe promover el turismo cultural, pero desde una visión desde abajo, desde lo popular, pp. $15-28$

Rivas, R. D.

preocupándose por la infraestructura; es decir, dotando de bienes y servicios a la gente, capacitándo desde la educación, salud, vivienda, transporte, comunicación, energía; aprovechando la iniciativa actual por la difusión del contenido cultural. Naturalmente, para que esto funcione se requiere de una estructura institucional superior, compuesta por el Estado - con una política clara y a largo plazo - la empresa privada y el pueblo en general con plena participación.

Es necesario tomar en cuenta que el turismo, si se sabe utilizar y redimensionar, puede ser un elemento de conocimiento recíproco entre los pueblos, pues contribuye a reforzar la paz, promueve la armonía, la colaboración, la solidaridad, la educación de los jóvenes y adultos, favorece el intercambio de conocimientos; además, constituye la mejor forma de financiamiento para la restauración de los lugares de interés histórico y artístico que forman parte a su vez del patrimonio; razón por la cual los pueblos más evolucionados han hecho un buen uso de su patrimonio cultural y el turismo.

Un ejemplo de lo anterior lo proporciona Costa Rica en donde vemos la cantidad de instituciones y personas que se benefician del turismo bien organizado. La generación de empleo en el ámbito turístico incluye actividades económicas como la construcción, industria textil, etc. En ese país hay programas culturales cada semana (sábados y domingos) en donde concientizan y educan al turista nacional en la preservación de los bienes naturales y culturales del país. La gente de esta forma es instruida, y esa instrucción le lleva a valorar lo que tienen $y$, por ende, a difundirlo.

En Costa Rica es desde 1885 que se emite la primera legislación sobre 
Turismo y capital social en El Salvador:

Una reflexión desde la antropología del desarrollo

parques nacionales lo que implica toda una tradición sobre la valoración de los recursos naturales en el país. No es por nada que la cuarta parte del país esta protegida como reserva natural y parques naturales. Además, la posibilidad de utilizar mano de obra en gran escala evita así la migración de las personas hacia los grandes centros urbanos.

\section{Algunos beneficios de un turismo bien organizado}

Son muchos aspectos y a la vez variados los beneficios, pero los más importantes y en términos generales son: generación de empleo: este es uno de los aspectos más positivos del desarrollo turístico por la diversidad de actividades que genera. En El Salvador, puede servir para reactivar aspectos como transporte, alojamiento, alimentación, recreación y organización de viajes, entre otros. Reactivación social: el turismo sirve para que la gente se conozca mejor, por eso ya no debe ser un derecho exclusivo de determinados sectores sociales como hasta no hace poco se presentaba, ni instrumento de lujo para un determinado sector de la sociedad nacional. El turismo debe ser para todos, que permita el acceso de los sectores de menor recurso a la recreación, partiendo de la premisa que se debe explotar el turismo pero no al turista. Lo social permite colocar los bienes turísticos en todos los estratos nacionales e internacionales; además, contribuye a fortalecer la confraternidad de los pueblos y a elevar su nivel de vida. Las vacaciones pagadas de los empleados públicos son una necesidad básica, tal como lo son la alimentación, vivienda y vestuario, por lo tanto, los espectáculos, los productos comerciales, artesanales, etc., deben formar parte de la sociedad sin discriminación alguna. En 10 religioso: el turismo permite realizar visitas a lugares de importancia religiosas para el creyente y en el marco de la historia nacional, en fin, permite visitas y peregrinaciones a todos los lugares que tienen significación para los creyentes. En la salud: el turismo proporciona a nacionales y extranjeros todas las posibilidades del reposo y diversión con todas las ventajas que ello conlleva. En lo psicológico: las múltiples ocupaciones y dificultades a que están sometidos los salvadoreños que viven en las ciudades provocan la acumulación de tensiones que el turismo puede aliviar temporalmente, despertando en los ciudadanos el gusto por lo nuevo frente a la rutina del diario vivir. En el deporte: el deporte es una buena motivación para el turismo, ya que permite realizar ejercicios donde se prueba la agilidad, la destreza o fuerza del cuerpo y el espíritu. El deporte crea y recrea la mente.

Un turismo bien planificado $-y$ con ello ya solventados los problemas de inseguridad social creada por los antisociales y la delincuencia organiza$\mathrm{da}-$ muy bien puede ejercitarse. El país es rico en diversidad topográfica; hay lagos, montañas, y muy bien podrían implementarse los senderos para caminatas largas y cortas, dependiendo del gusto del que lo requiera. Esto lo he visto y experimentado yo mismo en Austria, Suiza y Holanda, y ¿por qué no aquí entre nosotros?

Las escuelas deberían de implementar periódicamente las caminatas, que no solo contribuirían como otro medio de hacer deporte sino, a la vez, si se hace bien planificado, podría ser un buen medio para que los alumnos entren en contacto directo con la naturaleza, aprendan de la flora y la fauna. Estas caminatas - si fueran acompañadas de un profesor de biología o un botánico - ilustrarían a los alumnos en el conocimiento y la utilidad de muchas plantas. Solo viendo de cerca el medio es que se aprende a cuidar. Los

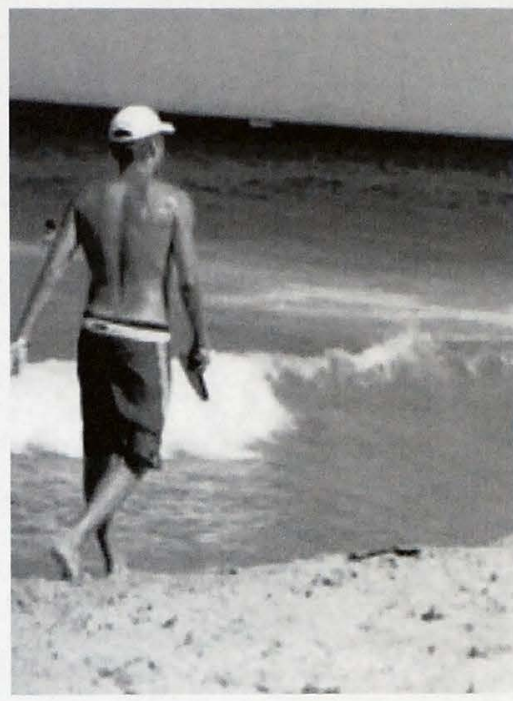

griegos son un buen ejemplo de este aspecto. Ellos viajaban con motivo de los juegos olímpicos, durante los cuales cesaban las hostilidades y los visitantes disfrutaban de la hospitalidad que se les brindaba. En materia deportiva el país ofrece variedad de sitios, ya sea al aire libre o en lugares cerrados: canchas de fútbol, básquetbol, futbolito, béisbol, tenis y otros; además, boliche y billar. El país es rico en lagos y playas, por lo que la explotación de los deportes que en estos espacios se practica sería algo que muy bien motivaría y calaría en el interés de muchos turistas. Habría que destinar algunos de estos lugares para la gente que nos visita. En el comercio: el turismo nacional o extranjero realizado por las diferentes vías de comunicación constituye una importante fuente de ingresos, pues los visitantes compran los productos que ofrece nuestro mercado. Naturalmente hay otros aspectos que muy bien pueden incluirse, y ejemplo de ellos son los negocios: aquí se incluyen las actividades profesionales privadas públicas e internacionales. Afortunadamente

Septiembre 2007, $\mathrm{N}^{\circ} .39$ 
Turismo y capital social en El Salvador: Una reflexión desde la antropología del desarrollo

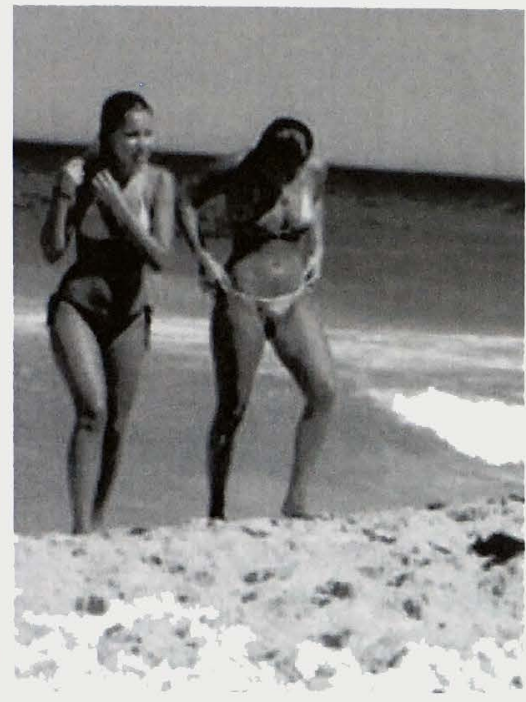

hay un buen número de hoteles que de buena manera están sabiendo explotar ese rubro y en forma eficiente, pero se necesita de más promoción. Vacaciones: es decir, el uso del tiempo libre en sitios como playas, montañas. lugares históricos, manifestaciones folklóricas, cultura popular, encuentro con poblaciones culturalmente diferenciadas, programas deportivos. Congresos, convenciones, reuniones: pueden ser de diferentes objetivos: técnicos, científicos, educativos, deportivos, religiosos of familiares.

En fin, hay muchas y variadas formas de ver y sacarle provecho a ese elemento que hoy llamamos turismo, y no necesariamente se trata de solo apuntarle a un beneficio. Sí, de lo que se trata es de saber involucrar a la comunidad en esa actividad y en todas sus dimensiones. Si el individuo y la comunidad no se apropian de este rubro y sus beneficios, será difícil convertirlo en algo sostenible: y sólo la sostenibilidad es lo que puede llegar a engendrar una cultura del turismo, sobre todo en naciones que en los últi- mos años han visto que puede ser una alternativa de desarrollo.

\section{Cultura y turismo como instru- mento para fortalecer la identidad local.}

Considero que para poder entender mejor el fenómeno del turismo hay que ligarlo al estudio de las relaciones entre Estado y desarrollo comunal en proceso, ya que eso nos dará las características sociales, políticas económicas existentes en las relaciones Estado y sociedad. Sólo de esta forma se puede llegar a tener una idea acerca del desarrollo organizativo nacional en la valoración y conservación del patrimonio tangible e intangible.

El turista, generalmente, no viaja a otros países para escuchar música, bañarse en piscinas o sólo para trasladarse, pues muchas veces goza de todo eso en su propio país. Así, considero que el turista vendrá a El Salvador buscando algo que no es común en su tierra: formas diferentes de cultura, pensar y de vivir. Es en ese contexto que elementos de la cultura local surgen como un verdadero canal de comunicación para el turista, ya que precisamente esos elementos son los que le permiten conocer nuestra forma de hablar, nuestras costumbres. comidas y bebidas, la arquitectura colonial - si es que la hay - y. por qué no, la arquitectura propia. ¿Existe una arquitectura propia en el país?

Las actividades turísticas deben planificarse tomando en cuenta los elementos característicos de las vivencias de los pueblos, ya que la idea de turismo contemplativo de los monumentos o recursos ambientales tiene que eliminarse, para dar paso al turismo social, que implica la interrelación entre los visitantes y los habitantes, que conlleva un intercambio económico y cultural. Elementos culturales locales - en todas sus manifestaciones - forman parte importante e inseparable del patrimonio cultural; por su medio el turista puede participar en los ritos populares, alboradas, nacimientos, bautizos, casamientos, entierros, velorios, fiestas, ferias, carnavales, etc. En consecuencia, el turista respetuoso se podrá llevar las mejores impresiones de nuestra cultura si convive algún tiempo con el pueblo in situ. Hay que saber aprovechar lo que tenemos, ya que a lo mejor hay turistas que desearían cortar café por alguna temporada o un par de días, lo mismo que al corte de la caña, del algodón (que ya se ha comenzado a sembrar otra vez). o experimentar una siembra de la milpa, o a lo mejor la tapizca y cosecha. Todos estos son factores que hay que tomar en cuenta.

La forma de hablar del pueblo, así como la historia y la geografía vistas a través de la cultura local. iluminan el camino para apoyar el turismo. Los topónimos, los nombres actuales de nuestros pueblos, las fechas importantes de la vida política y social, aunado a los datos históricos de los principales lugares, serán de mucha utilidad para propios y extraños. Para el caso, la fiesta del Divino Salvador del Mundo, el 6 de agosto, puede ser una excelente motivación, pues no solo beneficiaría al turismo religioso, sino que se fortalecería la fe cristiana.

La investigación y el conocimiento del espacio turístico natural, como de sus elementos básicos: topografía, vegetación. clima y hábitat; más los lugares históricos y típicos, ofrecen un buen campo de acción para el turismo interno. En consecuencia, todo esto debe traducirse en presupuesto para el Estado, invertir en eso, invertir en capital social, en capacitación. formar conciencia en las comunidades de su potencial y forjar un proyecto de desarrollo comunal. pues, de lo contrario, en la población no existirá ese sentimiento de apropiación, de creer 
Turismo y capital social en El Salvador:

Una reflexión desde la antropología del desarrollo

en uno mismo, ese sentimiento de que como ciudadano soy parte de la nación y que, por ende, estoy participando en un proyecto y, por lo tanto, ofrezco lo que tengo.

\section{¿De qué me sirve} decir que determinada dependencia estatal es la encargada de crear

\section{todo esto si no hay vinculación por parte del pueblo?}

Se trata, en otras palabras, de crear ese sentimiento de compromiso entre la población de que somos todos - los miembros de la comunidad - los que queremos fortalecer nuestra identidad local por medio del desarrollo de un turismo que beneficia a las mismas comunidades.

En un país en donde a lo largo de la historia ha existido un proyecto de nación, pero marginador y exclusivo, hay que tener cuidado cuando con determinados proyectos, $y$, en este caso, el turismo, se trata de involucrar a la nación en su totalidad, ya que hay que estudiar primero si verdaderamente a nivel local existe ese sentimiento de pertenencia comunitaria.

No hay que olvidar que muchas de nuestras localidades han sido trastocadas en sus pautas de relacionamiento y sociabilidad; primero por los efectos del conflicto armado, y luego por la migración, y, últimamente, muchas de estas localidades por el fenómeno de la violencia que también no es nada nuevo en el país.

Entonces, una reflexión como ésta nos lleva muy bien a redimensionar que el turismo enfocado sólo desde el Estado - por muy buenas intensiones que pueda tener - en vez de contribuir al desarrollo económico muy bien puede ser un elemento contraproducente que a corto plazo genere disputas a nivel interno con la creación de diversos grupos de interés. Si así fuera, esos proyectos sólo beneficiarían a un grupo particular y crearán en las localidades formas de desarticulación que no fomenta en nada ese sentimiento identitario.

El turismo también ha sido víctima del desenfreno, producto de la ambición de los políticos en turno. Ellos han formulado políticas erróneas, improvisadas, creando lo que se puede denominar seudoturismo cultural, porque ni se realiza para conocer los sitios que conforman el patrimonio de la humanidad, ni arrojan los resultados positivos que supone. Lo único que provoca el ese seudoturismo cultural es la destrucción del propio destino cultural y la amenaza de pérdida de la identidad. El Estado debe conformar una política de inversión en los parques y sitios arqueológicos; se debe conformar una política de Estado y no solo de un determinado departamento del Estado.

No hay que olvidar que hay ejemplos concretos en los que, durante los últimos años, la práctica del turismo cultural ha crecido significativamente por todo el mundo, teniendo unos efectos positivos indudables en el entorno social, funcional, urbanístico y patrimonial de los lugares de destino, convirtiéndose en uno de los fondos de provisión de recursos para el desarrollo de políticas de protección y rehabilitación del patrimonio. Se necesita de encontrar mecanismos para dar respuestas efectivas a la necesidad de formación y adquisición de instrumentos para los profesionales del sector turístico y de la gestión cultural y del patrimonio que desarrollan proyectos de turismo cultural. pp. $15-28$

Rivas, R. D.

El patrimonio cultural tangible, para que sea atractivo y por ende rentable, tiene que ser tratado como un producto que se pueda ofrecer. El reto está en cómo presentar este producto y hacerlo atractivo en una sociedad que no conoce de ese producto y por ese desconocimiento no lo disfruta e ignora su importancia.

\section{A manera de conclusión}

Del precedente podemos concluir que hay cierto interés en el país en desarrollar el turismo, pero hay algunos factores de carácter social como la creación de capital social en las comunidades que no se percibe en las estrategias del Estado. Son personas y empresas nacionales y extranjeras a título personal las que organizan cierta actividad turística. Pareciera que el Estado a lo que se dedica es a la apropiación de inversión más que al estímulo y el desarrollo comunal de las mismas comunidades, lo cual es una deuda histórica. No puede haber turismo si no se benefician a todos los sectores sociales de las comunidades.

Otro aspecto de considerar es el hecho de que si las comunidades no se involucran a corto y mediano plazo, no habrá ese sentido de concebir que "turismo somos todos" y que, por consiguiente, lo hacemos todos.

La otra conclusión que considero importante es el hecho de que hay que partir de la idea de un turismo de igualdad y no con ese sentimiento del que a ese europeo, americano o japonés que llega hay que atenderlo de otra forma. Es necesario superar esa idea colonialista. En ningún momento se puede justificar el ver esos actos organizados en el puerto de Acajutla a la llegada de un crucero y ver a esos connacionales vestidos con trajes inventados bailando y con sonrisas prefabricadas. Esas ideas preconcebidas de fomentar el turismo sólo contri- 
Turismo y capital social en El Salvador: Una reflexión desde la antropología del desarrollo

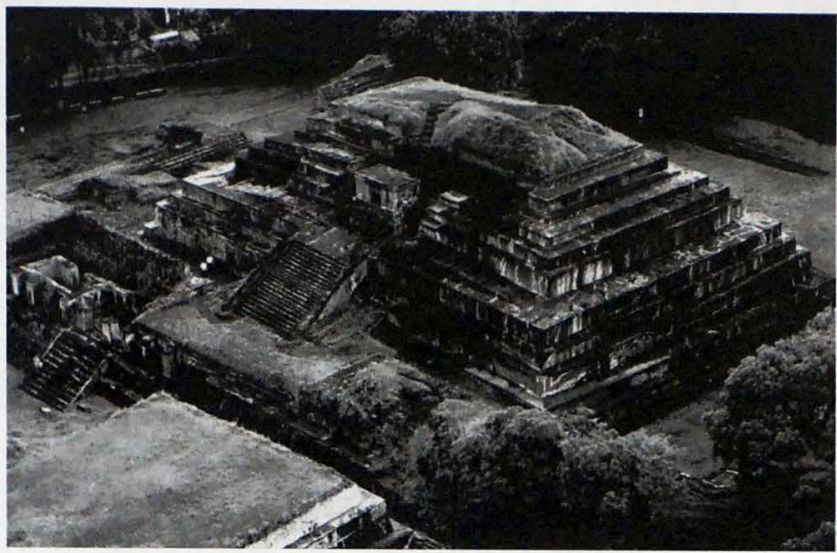

buyen a engrandecer el sentimiento de superioridad de otros que tanto ha costado a la humanidad y, sobre todo, a las ex colonias a lo largo y ancho del planeta y nosotros no somos la excepción. La promoción del turismo se debe ofrecer con naturalidad y, sobre todo, con honestidad.

El turismo puede ser una fuerza dinamizadora y un vector de diálogo entre los pueblos si se hace una gestión eficaz que establezca acuerdos entre el sector público y el privado. La formación y la sensibilización de la comunidad de acogida sobre el valor de su patrimonio también es determinante a la hora de asegurar que el turismo sea una fuente de prosperidad y de entendimiento en lugar de una amenaza.

En definitiva: urge de conocer nuestro rico patrimonio ya que ello es la síntesis simbólica de los valores identitarios de una sociedad que los reconoce como propios. Ello implica un proceso de reconocimiento, generalmente intergeneracional, de unos elementos como parte del bagaje cultural y su vinculación a un sentimiento de grupo. Reconocida en él, la comunidad se presenta a otros. En ese instante el bien concreto estará a salvo momentáneamente. Si bien su conservación no estará garantizada, al menos su destrucción y pérdida será sentida como propia.

El desarrollo del turismo, en todas sus dimensiones requiere de un plan de puesta en valor y resguardo de bienes para que estos adquieran carácter público.

Es conocido el hecho de que muchos pobladores locales conviven durante gran parte de su vida con su patrimonio, sin ni siquiera saberlo, por lo cual su conducta de agresión hacia el mismo no puede ser castigada ya que se efectúa sin intención.

También existen casos de personas que conocen el origen, pero que ignoran su valor, para ellos solo se trata de cosas viejas, que a través de los años tal vez algunos suelen recordar.

Para este tipo de situación se piensa en la concientización (entendiendo por concientización al trabajo de divulgación y extensión de los conocimientos científicos, por parte de la comunidad universitaria que realiza investigacio- nes en el territorio que comprende el patrimonio hacia la comunidad local, con el asesoramiento de personal idóneo en tareas de ese tipo) como una forma de contrarrestar el efecto negativo que implica el ejercicio de la ignorancia sobre las potencialidades de desarrollo científico y económico que encierra el patrimonio. En este sentido se necesitan acciones complementarias, por ejemplo: el trabajo de difusión y extensión del conocimiento adquirido ya mencionado.

Es por ello que el turismo, y en este caso - me refiero al cultural- no es una panacea de todos los problemas, ni tampoco un nuevo mecanismo para atraer nuevos turistas $y$, por consiguiente, más dinero. Constituyen una oportunidad para que anfitriones y turistas conozcan y entiendan mejor nuestro mundo para convertirlo en un espejo de nosotros mismo, para desarrollar nuestros gustos y emociones... nos lleva a una mejor calidad de vida mediante el alojamiento de nuestra vida cotidiana, paisajes y experiencias turísticas.

Cierto es que el turismo cultural puede revitalizar las antiguas tradiciones y componentes culturales y adaptarlos a la nueva situación. Sin embargo, una comunidad puede desaparecer en el anonimato si el producto no es notable, y diferenciador, sin contar que la actividad turística puede provocar la inflación de los precios, estimular la competencia en relación con los recursos y la intromisión en la vida privada de los residentes, así como una destrucción paulatina del patrimonio natural y cultural y esto ya comienza a ser un hecho en nuestro país.

Por ello las estrategias y políticas que alientan el mantenimiento y acrecentamiento de los recursos culturales

Septiembre 2007, N .39 
deben incluir un fuerte comportamiento educacional, participación de la comunidad, directrices de conservación y códigos de ética incluso para el visitante.

En la comunidad estas políticas sostenibles deben arraigarse entre los principios básicos, ideas y características de una cultura local en particular y no verse como un producto rentable:

Deben realizarse diversos programas educacionales para concentrar a la localidad en las particularidades del entorno cultural.

Debe formularse una estrategia de intervención de manera democrática y en asociación con la industria turística para promover la conciencia del patrimonio cultural, tanto tangible como intangible.

Respetar la integridad y las autenticidades culturales, la conservación de los recursos culturales y la interrelación existente entre patrimonio cultural, natural, y la esencia de la búsque-

\section{Referentes bibliográficos}

Cernea, Michael (coord.) Primero la gente. Fondo de Cultura Económica. México. 1995.

Dahl, G., y Rabo. A., eds. Kam-ap or Take-off. Local notions of development. Stockholm: Stockholm Studies in Social Anthropology. 1992.

Escobar, A.: Anthropology and the colonial encounter. American Ethnologist, $\mathrm{n}^{\circ}$ 18 (4), 1991.

Escobar, A. 'Anthropology and the development encounter: The Making and marketing of development anthropology.' American Ethnologist 18(4).1991.

Foster, George: Antropología aplicada. Fondo de Cultura Económica. México. 1995. da de desarrollo, el ser humano.

Por tanto una gestión patrimonial sostenible y responsable a través del turismo debe seguir algunos de los pasos:

Las actividades turísticas deben ser sostenibles ambiental, económica, social y culturalmente. El desarrollo y la gestión de las actividades turísticas deben guiarse por los objetivos, principios y compromisos establecidos en la Convención sobre la Diversidad Biológica

Todos los involucrados, incluyendo gobiernos, organizaciones internacionales, el sector privado y los grupos ambientales, deben reconocer sus responsabilidades comunes para alcanzar formas sostenibles de turismo. Deben desarrollarse políticas y, cuando sea apropiado, legislación, instrumentos e incentivos económicos ambientales para asegurar que las actividades turísticas cumplan con las necesidades de conservación.

Las actividades turísticas deben pla- nificarse en los niveles apropiados con vistas a integrar en todos los niveles las consideraciones socio-económicas, culturales y ambientales. Desarrollo, ambiente y planificación turística deben ser procesos integrados. Debe hacerse todos los esfuerzos para asegurar que los planes turísticos integrados sean implementados y observados

El turismo debe desarrollarse de forma que beneficie a las comunidades locales, fortalezca la economía local, emplee fuerza laboral local y, donde quiera que sea ecológicamente sostenible, use materiales locales, productos agrícolas locales y habilidades tradicionales. Deben introducirse mecanismos, incluyendo políticas y legislación, que aseguren el flujo de beneficios hacia las comunidades locales. Las actividades turísticas deben respetar las características ecológicas y la capacidad del ambiente local en el cual ellas se realizan. Debe hacerse todos los esfuerzos para respetar los estilos tradicionales de vida y culturas.
García Canclini, N. Culturas híbridas: Estrategias para entrar y salir de la modernidad. México, D.F.: Grijalbo. 1990.

Gimeno, Juan Carlos y Monreal, Pilar (editores): La Controversia del desarrollo. Instituto Universitario de Desarrollo y Cooperación (Universidad Complutense de Madrid), Madrid 1999.

Heitkamp, Thorsten. Die Peripherie von Madrid. Irpud, Dortmund 1997.

Horowitz M. 'Development anthropology in the Mid- 1990s.' Development Anthropology Network 12(1 y 2). 1994.

Little, P., y Painter, M. 'Discourse, politics, and the development process: Reflections on Escobar's 'Anthropology and the Development Encounter.' American Ethnologist 22(3). 1995.
Kottak, Conrad Philip: "Cuando no se da prioridad a la gente. Algunas lecturas sociológicas de proyectos terminados" en Primero La Gente, M. Cernea (coord.) Fondo de Cultura Económica. México 1995

Kottak, Conrad Philip: Antropología, una descripción de la diversidad humana. McGraw Hill, Madrid 1994.

Petras, James: "Conceptualizando el socialismo" en 50 años bastan. El libro del foro alternativo. Las otras voces del planeta. Talasa, Madrid 1995.

Wolf, Eric: Europa y la gente sin historia. Fondo de Cultura Económica. México. 1997. 